\title{
Erratum
}

Correction to: Induction of $\mathrm{G}_{1} / \mathrm{S}$ Phase Arrest and Apoptosis by Quercetin in Human Osteosarcoma Cells

Arch Pharm Res Vol 33, No 5, 781-785, 2010

\section{Induction of $G_{1} / S$ Phase Arrest and Apoptosis by Quercetin in Human Osteosarcoma Cells}

\section{Doo Kyo Suh ${ }^{1}$, Eul Jae Lee ${ }^{1}$, Hyung Chan Kim², and Jeong Hee Kim ${ }^{1}$}

${ }^{1}$ Department of Oral Biochemistry, College of Dentistry, Kyung Hee University, Seoul 130-701, Korea and ${ }^{2}$ Department of Oral Physiology, College of Dentistry, Kyung Hee University, Seoul 130-701, Korea

In the original version of the article titled "Induction of $\mathrm{G}_{1} / \mathrm{S}$ phase arrest and apoptosis by quercetin in human osteosarcoma cells", published in 33(5): 781-785 (DOI: 10.1007/s12272-010-0519-4), unfortunately an important footnote was missing by the author. This footnote reads as follows:

D. K. Suh and E. J. Lee contributed equally to this work. 